\title{
Widening Participation and Social Mobility: Encompassing and Integrating Learning Opportunities
}

\author{
Wendy Fowles-Sweet, University of the West of England, Bristol \\ Email: Wendy.Fowles-Sweet@uwe.ac.uk \\ John Barker, University of the West of England, Bristol \\ Email: John.Barker@uwe.ac.uk
}

DOI: https://doi.org/10.5456/WPLL.20.2.69

\begin{abstract}
Many regional universities occupy interesting positions between hi-tech, urban employers and learners, and learners from less socially or economically advantaged (including rural) backgrounds. Many such institutions have maintained their pre-92 roots in widening participation and providing employer-focused learning, and these are driven today through the inclusion of practice-oriented learning in their teaching strategies. Such institutions have a very strong presence in regional widening participation activities, and social mobility has a major part to play in who is likely to study at them.
\end{abstract}

The aim of this paper is to consider two distinct types of learners who are enabled in their studies by widening participation opportunities:

a) full-time undergraduate students who are beginning their lifelong learning

b) mature learners, already within a workplace environment, who enter higher education to enhance their careers.

Participation from both traditional and non-traditional groups in further and higher learning is considered essential to encourage economic growth and long-term social mobility. However, engaging the differing types of students to meet employers' requirements needs varying approaches.

Our findings show that:

a) Social mobility plays an important part in how full-time students develop and how they consider long-term careers in terms of their current focus on education.

b) Flexibility of learning is important for learners and employers to focus learning on both specific business requirements and individual professional development without losing the academic underpinning.

In both cases, employer needs have to be recognised when developing and delivering education to ensure professional as well as academic requirements are met to create 'graduate attributes'. 
This paper examines the balance between educational integrity and employer requirement. It focuses on examples of existing good practice within a specific institution that are designed to encourage those from non-standard academic backgrounds to achieve their potential. This is becoming particularly important with the advent of degree apprenticeships, which are likely to introduce a new demographic to higher education who might never have considered adult learning before. It also requires close collaboration with employers to ensure education provision meets the fundamental business needs within the local region.

Key words Degree apprenticeships; placements; work-based learning; pedagogy; econometrics

\section{Introduction}

Higher education (HE) is geared towards a socially mobile and economically sound population (Waller et al., 2014). However, the need to widen participation is now at the core of long-term HE development for two reasons:

- to upskill young, potentially economically productive individuals from all areas of society to meet long-term global challenges (Cameron and O'Hanlon-Rose, 2011)

- to create inclusive programmes of education and research that support both economic development, and creative and innovative, lifelong learning, especially for those already in the workplace (OECD, 2003).

Universities are often perceived as 'middle-class bastions' (Wride, 2014), and although many institutions are trying to widen participation and outreach to both young people and their regional communities, the influence and economics of the middle class dominate (Iannelli et al., 2016). This leaves a pool of people whose backgrounds do not prepare them for higher learning and so are lost to the wider world of innovation and creativity.

Some such students do overcome the social mobility barriers they face to find their way into HE. However, some of these see the opportunity to realise their dream of starting a degree to be the end goal in itself (Redmond, 2006) and find it difficult to refocus on the concept of lifelong professional development. This affects both young and more mature students; the challenge is to relate their academic learning to the work environment.

\section{Case Study Approach}

The impact of social mobility on learners is such a vast, potentially overwhelming topic that it can be difficult to identify particular themes to follow and develop. The authors' aim is to try to focus on factors that could improve students' situations, so a review of existing practice was chosen in the form of case studies. 
This paper uses observational case studies undertaken at the University of the West of England, Bristol (UWE) to illustrate some of the challenges that students face in relation to social mobility, and how they overcome them. An 'intensive approach' focusing on 'one specific phenomenon' was used, rather than an 'extensive approach' that would have utilised wider and more quantitatively diverse data and, therefore, produced more reliable conclusions (Swanborn, 2010, p. 13). This option was selected based on specific access to populations and the time constraints of finding an organisational partner that recreated both the size and scope of UWE's lifelong learning community. This approach means that the study has been unable to establish representative reliability, and therefore credibility that the findings would reflect a broader population, nationally or internationally (Neuman, 2014).

Nevertheless, this approach to case study methodology does enable the 'study of contemporary organizational phenomena in a real-life setting with an in-depth, holistic study of few or single cases' (Hoon, 2013, p. 522). This methodology led the study towards institutionally-specific findings, rather than creating a universal taxonomy for the findings (Byrne and Ragin, 2009; Yin, 2009; Felce, 2017). While the findings of this paper may be termed 'fuzzy' (Bassey, 1999), the use of case studies to form a body of evidence allows the conclusions to be drawn with the 'authentic voices of those within the research process' (Hamilton and CorbettWhittier, 2013, p. 162).

The paper explores two themes in particular: (1) how social differences between undergraduate students effects their attitude to professional development after graduation; and (2) why mature learners, from a workplace environment, choose to enter HE part time as their careers develop. In this paper we discuss UWE's current position and our intention to progress forward.

These case studies were selected to demonstrate the importance of employability to students and industry alike. The methodology is clear and should be easy for nonexperts to follow, and the report demonstrates the impact of the approaches taken, minimising the 'fuzziness' of the methodology, and listening to those directly involved. This in turn enables better evaluation of the usefulness of such activities, but it should not be assumed that the impact achieved in certain areas would automatically be achieved elsewhere. It is important to identify from the case studies the incremental steps that could be used generically and are suitable for a wide range of situations.

\section{Balancing Higher Education Core Principles with the Need for Employability}

To position the case studies, this investigation first explores the economic and academic implications to be considered when designing learning development opportunities. It then investigates the pedagogy implications of work-focused education. 


\section{Economic Needs}

\section{Employability}

The development of reflective skills through practice and work-based learning (WBL) makes learners more employable because they are absorbing skills and knowledge relevant to their roles (Huq and Gilbert, 2013). While this is a strength of WBL, it is also one of its weaknesses, owing to its focus on a particular workplace scenario, creating what Nixon et al. (2006, p. 13) calls an educational 'cottage industry supported by enthusiasts'. To counter this, the UWE modular learning outcomes for WBL tend to be generic, rather than subject-focused, allowing teaching staff and employers to shape learning specific to the students' particular needs. Although good in terms of a learner's practice, consideration must be given to the European Training Foundation (2013, p. 29) report that WBL is 'not sufficiently relevant to the economies'. So in effect, regionally WBL supports skills development, but nationally and globally this approach may not meet demand for skills.

WBL is significantly flexible enough to accommodate the needs of the micro-skills climate of an individual business, while still delivering competencies, skills and knowledge applicable across the national terrain. However, there is a creative tension between local and national requirements, which is explored in the next section using degree apprenticeships (DAs) and gender as examples.

\section{Econometrics, Gender and Degree Apprenticeship Horizons}

Econometrics can provide insights into the economic value of certain forms of education. The purpose of econometrics is to 'measure and estimate statistically the relationship between two or more economic variables' (Pass et al., 2016). It provides a useful statistical tool, one which is utilised to explore both the value of apprenticeships to a national economy and the differences in gender equality in the UK in the following sections of this paper.

In calculating the economic value of certain forms of education, the Department for Education utilised the net present value (NPV) indicator to attribute financial outputs to particular groups of graduates/completers. NPV is defined as the discounted value of future income from a particular investment, less the discounted value of expected costs' (Rutherford, 2013, no page). The Department for Business, Innovation and Skills' report on the effectiveness and cost-benefit of apprenticeships $(2015$, p. 5) outlines the clear financial benefits to the economy of individuals undertaking the following qualifications:

- $\quad$ apprentice graduate, level 2: average NPV $£ 61,000$

- $\quad$ apprentice graduate, level 3: average NPV $£ 88,000$

- HE graduate: average NPV $£ 108,000$.

Interestingly, the average NPV for HE graduates of $£ 108,000$ (Department for Business, Innovation and Skills, 2011, p. 34) can explain, in part, why the government is seeking to increase the number of individuals completing degree level apprenticeships, as well as the lower level foundation degree and National Vocational Qualification equivalents. If achieved, the expected NPVs would increase 
the socio-economic capital of the UK. Yet, further exploration identified a major discrepancy behind these figures.

DAs allow completing male and female graduates to receive the same degree as their full-time taught contemporaries. But will DAs close the gender gap in terms of pay and NPV? In 2011, UK male graduates from degree programmes had an NPV of $£ 120,500$ while their female counterparts were only valued at $£ 82,500$ (Department for Business, Innovation and Skills, 2011, p. 56).

This has interesting implications for UWE as the institution has a higher proportion of female than male students/graduates (15,239 women to 12,039 men in 2014/15; UWE, 2015). If the UWE gender imbalance is projected onto DA graduates, and the employability and skills of the female majority are enhanced by the job specific nature of the qualification, then potentially the NPV gap will decrease. This will be an interesting hypothesis to test in future evaluation and we expect any decrease in the gap to correlate closely with the apprenticeship sector, e.g. nursing or engineering.

Wider issues surrounding apprenticeships and gender will be a key factor determining the success, both economically and socially, of the DA programme. Simon and Clarke (2016, p. 579) state: 'apprenticeships as currently configured are not working for women and girls'. This is reinforced by the existing pay gap for female apprentices who, according to the Young Women's Trust (2016, p. 4), earn an hourly wage of $£ 4.82$, compared with $£ 5.85$ for their male counterparts. This is equivalent to an annual wage for women of $£ 2000$ less than men (Young Women's Trust, 2016). In spite of this inequality, over the last five years more women have registered for apprenticeships than men (Department for Education and Skills Funding Agency, 2016). We can extrapolate from this that the in-equality of pay is not actually negatively effecting the uptake of apprenticeships by women, which is worrying trend as it implies women simply accept the gap.

\section{Pedagogy and Andragogy}

\section{Educational Integrity}

A key concern of $\mathrm{HE}$ is that the focus on the economics of providing degree programmes, for example, DAs, could dilute the core principles of educational learning. A university education is distinctly different from a traditional apprenticeship, and there is an ongoing tension between academic education and the competency training expected by industry.

This theme has been an ongoing concern for both the Department for Business, Innovation and Skills (2015) and the Department of Education and Skills Funding Agency (SFA, 2016) as graduate attributes required to achieve a job do not always correlate with educational learning outcomes, particularly in subjects considered esoteric rather than vocational. While universities and employers have a long history of working together in research, there is still a lack of clarity when it comes to the relationship between learning outcomes and skill expectations (Barker, 2016). 
For example, through working closely with industry as part of employer-led groups called 'trailblazers' to develop degree apprenticeship standards, it has become very clear that some employers struggle to understand educational pedagogy (Antcliff et al., 2016). Therefore, there is a growing need for educationalists to bridge this gap. In parallel, employers need to ensure their professional requirements are achieved through the trailblazer process, and getting the pedagogic balance correct is difficult, particularly in the tight timescales required (Newton et al., 2015; Saraswat, 2016).

\section{Flexibility of Provision and Theoretical Underpinning of Skills}

A key feature of business engagement is the ability to deliver education in terms more favourable to industry than the standard academic year. This is arguably the greatest concern within industry when engaging with $\mathrm{HE}$ - minimising their employees' time away from the job (Rowe et al., 2016). The employer has to be a key stakeholder in defining learning requirements and delivery methodologies (Fowles-Sweet and Barker, 2014)

There are several options, including WBL, practice-based learning, distance learning and also short, sharp blocks of teaching. Although favoured by business, these are not traditional HE delivery methods, and can cause resource and staff engagement challenges (Campbell et al., 2013).

The key to good education is the pedagogical underpinning of the subjects involved. The delivery style must facilitate academic learning through evaluation and reflection - especially at undergraduate and master's level. For example, at UWE experience highlights that while industry wants block delivery to minimise 'time away from the desk' and coursework rather than exams, on particular industry-focused master's degrees, full-time students fare less well if assessment is shortly after block delivery, due to poor engagement. Such students can be overawed by the practical knowledge of industry-based students and are unused to the shorter time period in which to reflect and learn before assessment. Undertaking modules in block format can adversely affect the time students have to reflect, sometimes potentially tipping the module into a training scenario rather than an educational experience.

So, it could be argued that such employer-preferred block delivery is at odds with a pedagogically sound educational experience (Basit et al., 2015; Nielsen et al., 2015). A conflict between academic and business requirements can result in disagreement and distrust, breaking down the opportunities for mutual benefit. If HE is not careful, this tension is in danger of occurring during the process of setting the standards for DAs.

\section{The Learners}

At this point the focus returns to the learners. Knowing the requirements of employers and educationalists is vital, but it is important that course development also takes into account the students' needs, including their individual learning styles (as discussed by Daley et al., 2016; Rowe et al., 2016).

While the pedagogic focus needed for both young and mature students varies with personal learning styles, other external factors exist such as employers' requirements. So, how should these competing needs be dealt with? Can 
understanding the backgrounds of students enable HE to help students gain their required graduate outcomes?

This is explored by considering the issues facing two types of learners, both of whom are impacted by their environment and their personal backgrounds:

- $\quad$ young adults entering education without clear goals beyond graduation

- $\quad$ mid-career students wanting to improve their career opportunities.

\section{Social Mobility}

Alongside the economic and academic implications of developing learning opportunities, there are numerous other factors which stop students realising their potential. Two are now discussed, focusing on how students have dealt with them and what we, as academics, can learn from the process.

There are often barriers - real or imagined (Reay, 2011; Ganesh and Ratnakar, 2014; Lundgren and Poell, 2016) - perceived by students but not necessarily recognised by academics. UWE's aim is to try to raise awareness of these issues to enable colleagues to provide greater support to students and improve their future employability.

This paper looks at two such issues:

- culture: how HE is perceived

- class: traditional and non-traditional entry to HE

\section{Culture}

An individual's parents, and the culture they grow up in, have a range of educational influences on them, affecting their study and life choices from a very early age. Schlechter and Milevsky (2010) found a direct correlation between parental level of education and university entry for their children. Additionally, Parker and Williams (2011) highlight that in communities where education is not part of the culture, young people would prefer to work than go into FE or HE settings. This cultural difference, leading to low educational aspiration, has been of great concern for a number of years and is considered a key factor in skills shortages in science, technology, engineering and mathematics (STEM) subjects (Farrell and McHugh, 2017; Diekman et al., 2017).

Regional factors also play their part: although there are several universities in the west of England, individuals in Cornwall and Devon have limited access and HE facilities are only just starting to be set up in Somerset. Interestingly, the creation of facilities in Somerset is partially a by-product of the nuclear industry-based skills requirements for the Hinkley Point development. However, HE has simply not featured strongly in more rural areas and students are perhaps not as encouraged to consider it as their more urban-based peers, which is a recognised global concern within education (Fleming and Grace, 2016; Friesen and Purc-Stephenson, 2016). 


\section{Class}

The drive for universities to widen participation and inclusion has led to broad definitions around the concept of class. The Higher Education Statistics Agency (HESA) uses the National Statistics Socio-economic Classification's (NS-SEC) categorisation of occupation to group students' backgrounds in relation to the occupation of their highest earning parental figure (Rose and Pevalin, 2003). This scale ranges from 1 to 8 , and students whose parents' occupations fall within classification groups 4 to 7 are the target of widening participation measures (HESA, 2017). Point 4 on the scale includes professionals working for small employers; point 7 includes those employed in routine occupations. Individuals at point 8 are those who are long-term unemployed or who have never worked. Students whose parents do not fill in their occupation on the Universities and Colleges Admissions Service (UCAS) application form are defined as 'unknown' and classed as category 8, which could be providing a statistical bias to the number of graduates from low socioeconomic backgrounds (HESA, 2017). For the purposes of this paper, the range 4 to 7 indicates lower socio-economic status, while 1 to 3 signifies middle/upper class or intermediate/high socio-economic status.

Class has a major impact on entry to HE. Universities are often seen as middle class, immediately creating a barrier of perception for many potential students (Bathmaker et al., 2013). In their case study interviews, Parker and Williams (2011, p. 142) highlight that participants from lower socio-economic backgrounds refer to the HE environment as being 'not for the likes of us', and that they would 'rather get a job'. Often, although much effort is aimed at reducing these barriers, simple acts by individual educators can reinforce the perception that universities are middle class, such as assuming that students have access to a wide and supportive network throughout their studies (Jackson et al., 2015). The barrier created by this assumption is explored by Reay, Crozier and Clayton (2009, p. 111) who state that the different social audiences that universities recruit 'mutually shape and reshape each other', meaning that institutions become reflective of their own demographics. When applied to the broadness (or lack thereof) of a student's social and professional network, this perspective becomes problematic as it suggests a retraction of national and international employer relations in line with this experience. Redmond (2006) surmises that 'vocational and career-related motivations' play a crucial part in the decision of students from lower socio-economic backgrounds to enrol. This perspective puts the emphasis back on the institution to ensure that links with employers and placement providers are strong enough to overcome the challenges of a lack of social capital - consisting here of a mixture of economics, gender, culture and class, as well as other factors outside this study and the assumption that all students have a developed network of industry and personally supportive contacts.

In addition, some students from the NS-SEC classification groups 4 - 8 who have faced major challenges to even enrol onto degree programmes can feel that the enrolment is their ultimate goal (Quinn, 2004 and Reay et al., 2009). When interacting with them it can be seen that some may never have thought about the next step; indeed, some academics believe that they are simply worn out through 
their efforts to reach that point and emulate their middle-class peers (Loveday, 2015). When faced with the prospect of further challenges to achieve professional development, some students chose to ignore them or feel unable to engage.

An additional, institutional observation made by UWE is that there is a lack of student engagement with a range of activities offered to support graduate employability and professional development (for example, anecdotally, in 2016 this was true of around $40 \%$ of engineering undergraduate students). In order to improve engagement, academics need to support students through their concerns and provide them with the opportunities to develop themselves. From work undertaken over the last couple of years to encourage students' interest in industrial placements, it appears that focused engagement with professional development happens at different times for different students, perhaps as they gain maturity while they develop through their degree programmes. This is something which we intend to investigate in a future study.

\section{Case Study: Work Experience - Placements and Internships}

In 2015, UWE's Department of Engineering Design and Mathematics (EDM) initiated an extended induction programme at Level 2 that would support the academic personal tutorial process. The aim was to ensure all Level 2 full-time students had access to information that would help them look for placements and internships, and to help them prepare themselves for their third and fourth year and eventual graduation.

EDM works closely with the UWE careers services, which is nationally recognised for its student support, winning 'Best University Careers/Employability Service' in 2014 (National Undergraduate Employability, 2014). Generally, employability after graduation is high with, according to the Destination of Leavers from Higher Education (DLHE) 2016 survey, 96\% of UWE alumni employed and roles continue to be readily available in STEM subjects. However, the university felt that some students were not sufficiently prepared and were struggling to find graduate jobs. By introducing the extended induction in EDM, it was hoped students would engage with the professional development process earlier.

The induction programme conducted with the 2015/2016 cohort identified a number of points:

- Many did engage with the programme - initially $170+$ students, which constitutes the majority of the EDM Level 2 cohort. However, engagement faltered as time progressed, with some students not engaging at all. The value of the educational material offered was pertinent and relevant - why did some students stop engaging, and others not engage at all?

- Those learners who did engage responded well and provided appreciative feedback. Through the Staff/Student Representative Committee they stated that they liked the sessions, and suggested that early content be delivered in Year 1 to encourage students to consider summer work experience before Year 2. This has been instigated by the department since 2016. 
- More students approached the Placement Module Leader to discuss how and where to apply for year-long placements, and careers services provided excellent support and advice. Yet, overall, there was little improvement in placement numbers - why?

- Students who engaged with the programme entered Year 3 better prepared for their individual projects.

- Yet, some students still did not fully engage with professional development until close to graduation.

It became apparent that some students did not follow up on the Level 2 activities because they could not see why they were directly relevant to their studies. As it was extracurricular, it was perceived as less important than their academic studies.

By researching social mobility to help understand students' attitudes more clearly, and by identifying factors not before considered in the academic process, a number of points were identified.

\section{Timing of Engagement}

There is no single point of time at which students engage with professional development sessions. Although these sessions have been moved into Year 1, a low engagement should be expected. Unless attendance is enforced, students self-select, which in this case meant that around three quarters of the Year 1 cohort did not engage with the timetabled activities. However, it was decided that enforced attendance would be counterproductive.

Reiterating the importance of work-based experience early in Year 2 enabled the department to pick up a percentage of those students who missed out earlier, and focused the early starters further on their personal development. Some had found work experience during the summer; others had engaged early in identifying future work opportunities. This increased engagement to between 50-60\%, especially focusing on placements/internships and work experience.

Formal reminders are also required in Year 3, currently timetabled for 2017/2018. The less-engaged students suddenly become aware that their studies will soon be completed so tend to re-engage. Engagement opportunities at this stage again reinforce messages about career planning, which is an issue that looms more largely for those expecting to complete their studies after Year 3.

In summary, our findings suggest that academic leadership, patience and perseverance are needed. Academic support is vital to provide professional direction and demonstrate its validity and importance. The university's careers service also plays a hugely integral role in achieving these important graduate outcomes. Their willingness to raise awareness and engage with individuals by supporting applications and helping with interview techniques has a major impact on students. It appears that students focus on professional development prompts in their own time, so information needs to be reiterated regularly to be as inclusive as possible. 


\section{Difficulties finding Work Experience Opportunities}

Recognition came through preliminary analysis of the case study material that many students do not have the professional networks to find work experience opportunities. Personal confidence plays a big part in this - alongside social position. If a student has a network of family and friends with extensive contacts in business and industry, they have an immediate advantage which many put to good use (Bathmaker et al., 2013).

However, many students do not have this particular asset for a variety of reasons. For example, when trying to encourage a student to apply for placement, it was suggested they should ask their parents or family friends for help. The response was that their family and family's friends could not help as they did not have suitable contacts. The student relied solely on what the university could offer. Such students can sometimes find placements, but others lack resilience in the often drawn-out application process.

Others simply do not want such a protracted and difficult experience. They may consider short placements across a summer period, or are simply prepared to wait until they have to look for a graduate role. They cannot be forced into action, so alternative approaches to help their professional development are required.

\section{Possible Solutions}

One solution has been to develop further professional development workshops for Year 3 students, as mentioned above, in order to integrate the third year academic project process with the students' employability activities. The final year projects' module leader is developing a revised process to try to capture some transferable skills/graduate attributes within the project process. This should help students relate engineering to the wider society and environment, beyond the required technical skills.

Another, complementary solution has been to refocus the assessment used for placement students - which currently requires them to relate their placement learning to the UK Standard for Professional Engineering Competence for Engineers (Engineering Council, 2013) - to develop a new module called Engineering and Society. This pairs third year engineering students working with UWE's teaching students in order to engage primary school children with STEM. Third year students then have to relate this experience to their personal competency development, resulting in an initial career plan that helps them focus on their graduate opportunities while giving them an awareness of wider social issues. The research project leading to this module found that students had a wider comprehension of engineering and outreach, and an appreciation of its societal implications. We expect this to be developed further via the module.

The Engineering Council requires engineers to have competencies in societal learning and knowledge. These are seen as valuable graduate attributes by employers, as evidenced by the recent DLHE results which illustrate that $92 \%$ of engineering, design and mathematics students are employed in a professional or 
managerial role within six months of graduating (UWE, 2017) compared with the national average of $71 \%$ (HESA, 2017).

\section{Experiential Lessons in Best Practice}

Our experience with these student groups suggests the following recommendations:

- do not assume all students are at the same 'starting point'

- persevere in incremental steps - continually encourage, but do not try to force engagement

- link professional development with assessment

- engage staff, including academic tutors/supervisors and professional services, such as careers experts.

\section{Case Study: Work-Based Learning}

The offer of WBL, practice-based learning and more choice in vocational education and training (VET) has widened the doors of HE to a large number of learners from a range of diverse backgrounds. The impact of WBL on personal social capital has been the subject of various studies (Billett and Pavlova, 2005; Avis, 2009; European Training Foundation, 2013; Andersson et al., 2014) as the drive towards a 'skilled workforce' leading to economic prosperity has gathered pace politically (Department for Business, Innovation and Skills, 2015b). The key features of transforming socioeconomic horizons through WBL impacting both the individual and society are now discussed.

\section{Benefits of WBL for the Individual}

\section{Personal confidence and soft skills}

Heyler (2008) connects competency development through WBL with the growth of personal confidence. Hyland (2003), Lester and Costley (2010) and Edwards (2013) also identify similar links. Enhancing competency development enables learners to better form and manage relationships within the workplace, leading to the development of transferable skills, such as team working and communication (European Training Foundation, 2013; Glass et al., 2002; Rossin and Hyland, 2003). It also is interesting to reflect on the climate in which this breeds: Hager (2000, p. 61) describes the improvement in decisions and judgements of individual vocational learners as impacting 'the world'. However, the team that employees situate themselves within, the hierarchy supporting their team, and the organisational culture are just as significant as the subjective learner impact in Hager's view.

Students undertaking WBL at UWE complete a learning contract, which is signed off by their line manager and, by extension, is approved within the workplace environment. However, several students in the Faculty of Health and Applied 
Sciences have noted anecdotally that they have conducted their assessed work covertly, and without the express knowledge of their line manager. This brings certain ethical considerations to bear, and also potentially undermines the findings of their work, which is naturally driven towards motivating change within the workplace.

\section{Career Progression}

The growth of personal confidence and skills, with the ability of the individual learner/professional to reflect critically on their performance, leads to an improved quality of work and career progression, which benefits society (European Training Foundation, 2013, p. 20). Other studies have also highlighted the links between career advancement and vocational education (Bimrose et al., 2005; Brown et al., 2007) and Brown's (2004) paper considering engineering graduates interestingly highlights that people who do not engage with learning and development in their 20 's can actually see a downward employment spiral.

However, within UWE's Department of Nursing and Midwifery there is a long history of utilising WBL programmes, such as the Professional Development Awards, to support an upwards career spiral. Many nurses and midwifes construct a jigsaw of Continuing Professional Development and professional experience, which is gathered together in a Professional Development Award. They use WBL to consolidate their knowledge, experience and skills in the final summative assessment and several students have moved from being Healthcare Assistants (Band 5) to Advanced Practitioners (Band 7) using this route.

\section{Widening Participation}

HE's use of widening participation initiatives is predicated on the need to recruit students from under-represented groups to enter 'conventional taught courses straight from school or college' (Walsh, 2008, p. 8). This preference for standardised HE routes means that practical-based routes such as WBL and VET are sometimes viewed as 'devalued' (Reay, 2011, p. 1), or as 'lower-order qualifications' (Mumford and Roodhouse, 2010, p. 77). However, it is worth noting that in Bovill's (2013) case study, students with lower tariff points (80 tariff points) who enter a work-based foundation degree programme achieve a higher than average classification qualification in comparison with students who have up to 250 UCAS points.

The drive towards inclusion and widening participation within WBL is apparent in the rejection of the traditionalist notion that learning only takes place in formal environments (Brennan and Little, 1996). The ability of WBL to accommodate and accredit learning from a variety of professionals across the full academic spectrum (i.e. post-16 education) means that it is applicable to both skilled and unskilled professionals and so, in its essence, opens the door to a diverse set of learners (Nevala and Hawley, 2011). Nevertheless, criticism of this open approach exists, such as that provided by Lester and Costley (2010, p. 569) who consider that because of a lack of 'substantive curriculum, no written examinations or set assignments' WBL is 'less rigorous or simply inferior'. 
However, this is counter to UWE institutional experience. As part of the Professional Development Awards at UWE (which had 60+ new entrants in total in 2015/16), within the Faculty of Health and Applied Sciences all learners complete a 'learning contract' to produce an assignment and fulfil the learning outcomes of the required modules. Other examples of this structured approach are documented in Anderson et al. (1998), Lyons and Bement (2001), and Hassanpour et al. (2015). Although it might be argued that this may be more about the methods applied institutionally, Harvey (2008, p. 105) states that 'a wide variety of [WBL] models and approaches have been developed', and therefore consistency across the HE sector is the more pertinent issue.

\section{Conclusions}

The relationship between social capital, professional development and WBL is complex and interrelated when viewed through the prism of the individual and society. The presence and increasing importance of vocationally-led learning across $\mathrm{HE}$ opens the door for further inclusion. However, in the case of placements, work experience and WBL, it also opens new avenues for those with existing social capital to reinforce pre-existing class and cultural bias.

Nevertheless, early professional development focuses individuals on their competencies and careers, and provides employers with confidence that their new graduates have the appropriate attributes. While HE recognises this and tries to support the process, the challenge remains as to how to engage learners themselves.

The positive benefits of WBL as a mode of education are hugely influential on an individual's confidence and self-esteem. This can lead to career progression, which in turn allows the development of economic capital. The inclusive entry requirements for modules/programmes widen the doors for new and so-called 'second chance' learners. However, the benefits of practice-focused and WBL are still regional, improving many opportunities locally. The localism of this particular mode of learning only partially opens up opportunities for national skills development and employability. Further focus in this area, in conjunction with a heightened awareness of social mobility issues, can create opportunities for a more coherent approach to integrating inclusivity in $\mathrm{HE}$.

This paper has reinforced the theory that social capital impacts on both individual competency and the national economy. There are various strategies available within HE to try to mitigate some of these issues, but as a sector there is still some way to go to support the development of consistent social capital for all students. Using the case studies identified here and in other research may help to broaden academic understanding of the issues students face, and provide possible solutions, perhaps sparking innovation based upon their success. Further research, as discussed, will help develop some of the incremental stages towards achieving this goal. 


\section{References}

Anderson, G., Boud, D. and Sampson, J. (2012) 'Qualities of Learning Contracts' in John Stephenson and Mantz Yorke (eds.) Capability and Quality in Higher Education, 2nd edn, London/New York: Routledge.

Andersson, R., Nabavi, P. and Wilhelmsson, M. (2014) 'The Impact of Advanced Vocational Education and Training on Earnings in Sweden', International Journal of Training and Development, 18, 4: 256-270.

Antcliff, V., Baines, S. and Gorb, E. (2016) 'Developing Your Own Graduate Employees: Employer Perspectives on the Value of a Degree Apprenticeship', Higher Education, Skills and Work-Based Learning, 6, 4: 378-383.

Avis, J. (2009) 'Work-based learning: knowledge, practice and transformation', 18 February 2009. [Online]. Available at http://www.esri.mmu.ac.uk/seminars/knowledge.pdf (accessed: 15 November 2016).

Barker, J. (2016) 'Researching the Skills Base of the Modern Engineer: Embracing Industry, Education and People' in P. Nottingham and E. Nikolou-Walker (eds.) University Association of Lifelong Learning: Work and Learning Network Annual Conference, London: University Association of Lifelong Learning.

Basit, T.N., Eardley, A., Borup, R., Shah, H., Slack, K. and Hughes, A. (2015) 'Higher Education Institutions and Work-Based Learning in the UK: Employer Engagement Within a Tripartite Relationship', Higher Education, 70, 6: 1003-1015.

Bassey, M. (1999) Case Study Research in Educational Settings, Open University Press: Buckingham.

Bathmaker, A., Ingram, N. and Waller, R. (2013) 'Higher Education, Social Class and the Mobilisation of Capitals: Recognising and Playing the Game', British Journal of Sociology of Education, 34, 5-6: 723-743.

Billett, S. and Pavlova, M. (2005) 'Learning Through Working Life: Self and Individuals' Agentic Action', International Journal of Lifelong Education, 24, 3: 195-211.

Bimrose, J., Barnes, S.A. and Brown, J. (2005) A systematic literature review of research into career-related interventions for higher education. Warwick: Institute for Employment Research, University of Warwick. [Online]. Available at https://www.hecsu.ac.uk/assets/assets/documents/Literature review.pdf (accessed: 13 October 2017).

Bovill, H. (2013) 'It's a RAP? Retention, Attainment and Progression: Raising Tariff on Entry and the Impact Upon Widening Participation for Work-Based Students', Widening Participation and Lifelong Learning, 15, 1: 39-53.

Brennan, J. and Little, B. (1996) A review of work based learning in higher education. London: Department for Education and Employment. [Online]. Available at 
https://pdfs.semanticscholar.org/fa4e/12966376e52e2e0fc0fc8a5411f89f30e656.pdf (accessed: 5 December 2017).

Brown, A. (2004) 'Engineering Identities', Career Development International, 9, 3: 245-273.

Brown, A., Kirpal, S. and Rauner, F. (eds.) (2007) Identities at Work, Dordrecht: Springer.

Byrne, D.S. and Ragin, C.C. (2009) The SAGE Handbook of Case-Based Methods, London: SAGE.

Cameron, R. and O'Hanlon-Rose, T. (2011) 'Global Skills and Mobility Challenges and Possibilities for VET: A Cross-Border Cross-Sectoral Case Study', International Journal of Training Research, 9, 1-2: 134-151.

Campbell, M., Saltmarsh, S., Chapman, A. and Drew, C. (2013) 'Issues of Teacher Professional Learning Within 'Non-traditional' Classroom Environments', Improving Schools, 16, 3: 209-222.

Daley, J., Coyle, J. and Dwyer, C. (2016) 'Sheffield Hallam University and Nestlë:

Developing Future Leaders with the Chartered Manager Degree Apprenticeship - A Partnership Approach', Higher Education, Skills and Work-Based Learning, 6, 4: 370377.

Department for Business Innovation and Skills (2011) The returns to higher education qualifications. (BIS research paper number 45). London: Department for Business, Innovation and Skills. [Online]. Available at https://www.gov.uk/government/uploads/system/uploads/attachment data/file/324 19/11-973-returns-to-higher-education-qualifications.pdf (accessed: 4 December 2016).

Department for Business, Innovation and Skills (2015a) Measuring the net present value of further education in England. (BIS research paper number 228). London:

Department for Business, Innovation and Skills. [Online]. Available at https://www.gov.uk/government/uploads/system/uploads/attachment data/file/435 166/bis 15323 Measuring the Net Present Value of Further Education in Engla nd.pdf (accessed: 4 December 2016).

Department for Business, Innovation and Skills (2015b) 2010 to 2015 government policy: further education and training. London: Department for Business, Innovation and Skills. [Online]. Available at: https://www.gov.uk/government/publications/2010-to2015-government-policy-further-education-and-training/2010-to-2015-governmentpolicy-further-education-and-training (accessed: 2 November 2016).

Department for Business, Innovation and Skills and the Skills Funding Agency (2016) 'Apprenticeship programme starts by age, gender and level (2002/03 to 2012/13)', June 2014. [Online]. Available at https://www.gov.uk/government/uploads/system/uploads/attachment data/file/317 564/apprenticeship-starts-by-age-gender-level.xls (accessed: 3 November 2016).

Diekman, A.B., Steinberg, M., Brown, E.R., Belanger, A.L. and Clark, E.K. (2017) 'A Goal Congruity Model of Role Entry, Engagement, and Exit: Understanding Communal 
Goal Processes in STEM Gender Gaps', Personality and Social Psychology

Review, 21, 2: 142-175.

Edwards, K. (2013) 'Moments of Possibility: An Exploration of Adult Participation in WorkBased Learning', Widening Participation and Lifelong Learning, 15, 4: 65-80.

Engineering Council (2013) 'UK-SPEC UK standard for professional engineering competence'. [Online]. Available at

http://www.engc.org.uk/engcdocuments/internet/Website/UKSPEC\%20third\%20edition\%20(1).pdf (accessed: 17 March 2017).

European Training Foundation (2013) Work-Based Learning: Benefits and Obstacles - A Literature Review for Policy Makers and Social Partners in ETF Partner Countries. Turin: European Training Foundation. [Online]. Available at http://www.etf.europa.eu/web.nsf/pages/Work based learning (accessed: 11 October 2016).

Farrell, L. and McHugh, L. (2017) 'Examining Gender-STEM Bias Among STEM and NonSTEM Students Using the Implicit Relational Assessment Procedure (IRAP)', Journal of Contextual Behavioural Science, 6, 1: 80-90.

Felce, A. (2017) 'The Hub in a Pub: University of Wolverhampton Apprenticeship Hub', Higher Education, Skills and Work-Based Learning, 7, 1: 70-78.

Fleming and Grace (2016) Fleming, M.J. \& Grace, D.M. 2016, "Agents of aspiration: the (often unintended) benefits to university students working in outreach programmes", Educational research (National Foundation for Educational Research in England and Wales), 58, 3: 300-318.

Fowles-Sweet, W. and Barker J. (2014). Academia and employers hold the stakes, students get their choice of cake, presented at UALL Work Based Learning Annual Conference, Middlesex University, 2014 (unpublished).

Friesen, L. and Purc-Stephenson, R.J. (2016) 'Should I Stay or Should I Go? Perceived Barriers to Pursuing a University Education for Persons in Rural Areas', Canadian Journal of Higher Education, 46, 1: 138-155.

Ganesh, A. and Ratnakar, U.P. (2014) 'Learning Preferences of PG and UG Students: Application of VARK', SCMS Journal of Indian Management, 11, 3: 26-36.

Glass, A., Higgins, K., and McGregor, A. (2002) Delivering work based learning. Edinburgh: The Stationery Office Bookshop.

Hager, P. (2000) 'Knowledge that works: judgement and the university curriculum' in Colin Symes and John McIntrye (ed.) Working Knowledge: the New Vocationalism and Higher Education, Buckingham: Open University Press.

Hamilton, L. and Corbett-Whittier, C. (2013) Using Case Study in Education Research, Los Angeles: SAGE. 
Harvey, M. (2008) 'Understanding the Cost Implications of Work-Based Learning', in Jonathan Garnett and David Young (ed.) Work-Based Learning Futures II, Middlesex/Bolton: University Vocational Awards Council.

Hassanpour, B., Che-Ani, A.I., Usman, I.M.S., Johar, S. and Tawil, N.M. (2015) 'Lifelong Learning in Architectural Design Studio: The Learning Contract Approach', International Education Studies, 8, 1: 1-8.

Higher Education Statistics Agency (HESA) (2017) Destinations of leavers from higher education in the United Kingdom for the academic year 2015/16. Cheltenham: DLHE. [Online]. Available at https://www.hesa.ac.uk/news/29-06-2017/sfr245destinations-of-leavers (accessed: 17 November 2017).

Heyler, R. (2008) 'Employer Engagement: The New Widening Participation?', Widening Participation and Lifelong Learning, 10, 3: 14-21.

Hoon, C. (2013) 'Meta-Synthesis of Qualitative Case Studies: An Approach to Theory Building', Organizational Research Methods, 16, 4: 522-556.

Huq, A. and Gilbert, D.H. (2013) 'Enhancing Graduate Employability Through Work-Based Learning in Social Entrepreneurship: A Case Study', Education + Training, 55, 6: 550-572.

Hyland, T. (2003) 'Work-Based Learning Programmes and Social Capital' Journal of InService Education, 29, 1: 49-60.

Iannelli, C., Smyth, E. and Klein, M. (2016) 'Curriculum differentiation and social inequality in higher education entry in Scotland and Ireland', British Educational Research Journal, 42, 4: 561-581.

Jackson, C., Dempster, S. and Pollard, L. (2015) "They just don't seem to really care, they just think it's cools to sit there and talk': laddism in university teaching-learning contexts', Educational Review, 67, 3: 300-314.

Lester, S. and Costley, C. (2010) 'Work-Based Learning at Higher Education Level: Value, Practice and Critique', Studies in Higher Education, 35, 5: 561-575.

Loveday, V. (2015) 'Working-Class Participation, Middle-Class Aspiration? Value, Upward Mobility and Symbolic Indebtedness in Higher Education', The Sociological Review, 63, 3: 570-588.

Lundgren, H. and Poell, R. (2016) 'On Critical Reflection: A Review of Mezirow's Theory and Its Operationalization', Human Resource Development Review, 15, 1: 3-28.

Lyons, F., and M. Bement (2001) 'Setting the Standards: Judging Levels of Achievement' in David Boud and Nicky Solomon (ed.) Work-Based Learning: A New Higher Education?, Buckingham: SRHE/Open University Press.

Mumford, J.G. and Roodhouse, S. (2010) Understanding Work-Based Learning, Farnham: Gower. 
National Undergraduate Employability Awards (2014) 'NUE awards 2014'. [Online]. Available at http://nueawards.co.uk/archive-2014.php (accessed: 27 October 2017).

Neuman, W.L. (2014) Social Research Methods: Qualitative and Quantitative Approaches, 7th edn, Harlow: Pearson.

Nevala, A-M. and Hawley, J. (2011) Reducing early school leaving in the EU. Brussels: European Parliament. [Online]. Available at http://ec.europa.eu/social/BlobServlet?docId=9591\&langId=en (accessed: 2 November 2016).

Newton, B., Gloster, R., Miller, L. and Buzzeo, J. (2015) Evaluation of the apprenticeship trailblazers: interim report (BIS research paper number 213). London: Department for Business, Innovation and Skills. [Online]. Available at https://www.gov.uk/government/uploads/system/uploads/attachment data/file/627 975/bis-15-130-evaluation-of-the-apprenticeship-trailblazers-interim-report.pdf (accessed: 8 March 2017).

Nielsen, D., Ieromonachou, P., Lin, Y. and White, A. (2015) 'Revision of Curricula in Higher Education Service Provision: For Better Learning Engagement and Collaborative Learning', Procedia Manufacturing, 3: 3583-3590.

Nixon, I., Smith, K., Stafford, R. and Camm, S. (2006) Work-based learning: illuminating the higher education landscape. York: Higher Education Academy. [Online]. Available at https://www.heacademy.ac.uk/system/files/wbl illuminating.pdf (accessed: 5 December 2017).

Organisation for Economic Co-operation and Development (OECD) (2003) Education policy analysis - 2003 edition. Paris: OECD. [Online]. Available at

https://www.oecd.org/edu/school/educationpolicyanalysis-2003edition.htm (accessed: 18 October 2016).

Parker, L. and Williams, R. (2011) 'Higher Education and Regional Transformation in the UK: Social and Cultural Perspectives', Journal of Adult and Continuing Education, 17, 1: $130-146$.

Pass, C.L., Davies, L. and Lowes B. (eds.) (2016) Collins Dictionary of Economics, London: Collins. [Online]. Available at http://search.credoreference.com/content/entry/collinsecon/econometrics/0 (accessed: 11 January 2017).

Quinn, J. (2004) 'Understanding Working-Class 'Drop-Out' From Higher Education Through a Sociocultural Lens: Cultural Narratives and Local Contexts', International Studies in Sociology of Education, 14, 1: 57-74.

Reay, D. (2011) 'Schooling for Democracy: a Common School and a Common University? A Response to 'Schooling for Democracy", Democracy \& Education, 19, 1: 1-4.

Reay, D., Crozier, G. and Clayton, J. (2010) "Fitting In' or 'Standing Out': Working-Class Students in UK Higher Education', British Educational Research Journal, 36, 1, 107124. 
Reay et al. (2009) Rowe, L., Perrin, D. \& Wall, T. 2016, "The Chartered Manager Degree Apprenticeship: trials and tribulations", Higher Education, Skills and Work-Based Learning, 6, 4: 357-369.

Redmond, P. (2006) 'Outcasts on the Inside: Graduates, Employability and Widening Participation', Tertiary Education and Management, 12, 2: 119-135.

Rose and Pevalin (2003) Rose, D. and Pevalin, D.J. (eds) (2003) A Researcher's Guide to the National Statistics Socioeconomic Classification. London: Sage Publications.

Rossin, D. and Hyland, T. (2003) 'Group Work-Based Learning Within Higher Education: An Integral Ingredient for the Personal and Social Development of Students', Mentoring \& Tutoring: Partnership in Learning, 11, 2: 153-162.

Rowe et al. (2016) Rowe, L., Perrin, D. \& Wall, T. 2016, "The Chartered Manager Degree Apprenticeship: trials and tribulations", Higher Education, Skills and Work-Based Learning, vol. 6, no. 4, pp. 357-369.

Rutherford, D. (2013), Routledge Dictionary of Economics. London, UK: Routledge. [Online]. Available at http://search.credoreference.com.ezproxy.uwe.ac.uk/content/entry/routsobk/net pr esent value/0 (accessed: 20 November 2016).

Saraswat, A. (2016) 'Higher Apprenticeships and the New Apprenticeship Standards: Perceived Potential and Limitations', Higher Education, Skills and Work-Based Learning, 6, 4: 401-416.

Schlechter, M. and Milevsky, A. (2010) 'Parental Level of Education: Associations with Psychological Well-Being, Academic Achievement and Reasons for Pursuing Higher Education in Adolescence', Educational Psychology, 30, 1: 1-10.

Simon, L. and Clarke, K. (2016) 'Apprenticeships should work for women too!', Education + Training, 58, 6: 578-596.

Swanborn, P. (2010) Case Study Research: What, Why and How?, London: SAGE.

University of the West of England, Bristol (UWE) (2015) 'Student demographics'. [Online]. Available at http://www1.uwe.ac.uk/about/factsandfigures/studentdemographics.aspx (accessed: 15 December 2016).

University of the West of England, Bristol (UWE) (2017) 'Engineering design and mathematics graduate destinations'. [Online]. Available at http://www1.uwe.ac.uk/about/ourstory/employability/graduatedestinations/engineer ing.aspx (accessed: 17 November 2017).

Waller, R., Holford, J., Jarvis, P., Milana, M. and Webb, S. (2014) 'Widening Participation, Social Mobility and the Role of Universities in a Globalized World', International Journal of Lifelong Education, 33, 6: 701-704.

Walsh, A. (2008) What is distinctive about work-based knowledge and learning? York: The Higher Education Academy - Workforce development - July 2008. [Online]. 
Available at

https://www.heacademy.ac.uk/system/files/wfd what is distinctive about wb kno wledge and learning.pdf (accessed: 20 December 2016).

Wride, A. (2014) Universities remain bastions of middle class culture', The Telegraph, 14 April. [Online]. Available at

http://www.telegraph.co.uk/education/universityeducation/10764702/Universitiesremain-bastions-of-middle-class-culture.html (accessed: 20 December 2016).

Yin, R.K. (2009) Case Study Research: Design and Methods, 4th edn, Los Angeles: SAGE.

Young Women's Trust (2016) Making apprenticeships work for young women. London: Young Women's Trust. [Online]. Available at http://www.youngwomenstrust.org/assets/0000/2906/Making Apprenticeships Wor $\mathrm{k}$ for Young Women.pdf (accessed: 10 January 2016). 